\title{
Investigation and Research on the Financial Literacy of Rural Residents in Wuling Mountainous Area Against the Background of Rural Revitalization*
}

\author{
Zhengwang Li \\ School of Finance \\ Zhongnan University of Economics and Law \\ School of Finance \\ Hubei University of Economics \\ Wuhan, China 430074
}

\author{
Kai Wang \\ School of Finance \\ Hubei University of Economics \\ Wuhan, China 430205
}

\begin{abstract}
Based on the field research of the financial literacy and financial needs of rural residents in Wuling mountainous area, this paper understands the basic situation, financial awareness, financial knowledge, financial behavior, financial skills and Internet resources of rural residents, and understands the financial literacy of rural residents in the area by evaluating and analyzing the financial awareness, financial knowledge, financial behavior and financial skills of the rural residents in the area. Three suggestions are put forward: Firstly, all departments shall spread financial knowledge in the countryside; secondly, rural financial institutions should provide diversified financial services for rural revitalization, allocate financial resources to key areas and weak links in rural economic and social development; thirdly, it is necessary to improve financial infrastructure construction in rural areas, rationally arrange financial service institutions, and improve the efforts of information construction.
\end{abstract}

Keywords-Wuling mountainous area; financial literacy; financial awareness; financial behavior

\section{INTRODUCTION}

In recent years, inclusive finance has been developing in China, especially in the process of precision poverty alleviation, and China has increased financial capital investment and policy support in rural areas. The coverage rate of banking outlets have greatly increased in rural areas in China, the agriculture-related loans have further increased, and the new agricultural economy is developing continuously. In the process of developing "agriculture, rural areas and farmers", rural areas not only have problems such as shortage of funds, information asymmetry, large agricultural investment, long cycle, high risk and high production cost, but also the rural economic development is affected by the financial literacy of rural residents. On the one hand, due to the lack of financial knowledge and

*Fund: Acknowledgment to the support of China Foundation for Development of Financial Education; this paper is a stage achievement of the provincial teaching research project of colleges and universities in Hubei Province, "The Research on Model "1+N" for the Collaborative and Innovative Cultivation of Practical Financial Talents (2017399)". economic ability, it is difficult for rural residents to obtain the trust of financial institutions such as banks, and therefore they cannot obtain sufficient credit financing; on the other hand, their financial literacy is not high, so they cannot obtain sufficient financing supply information in time, and can't reasonably arrange financial behaviors.

The concept of financial literacy was first proposed by foreign scholars Noctor M et al in 1992. The study concludes that financial literacy is the ability of a person to use and manage funds through informed judgment and effective decisions. Since then, domestic and foreign scholars' definition of financial literacy can be broadly divided into five categories: understanding of financial concepts (Braunstein and welch 2002; Vitt et al, 2000), ability to communicate financial concepts (Fox, Bartholimae, and Lee, 2005), ability to manage personal finances (Chen and Volpe, 2002), techniques for making appropriate financial decisions (Rhein and Toussaint-Comeau, 2002) and confidence in effectively planning future financial needs (Koenig, 2007). In 2008, the US President's Advisory Council on Financial Literacy (PACFL) officially proposed: financial literacy refers to the ability to use knowledge and skills to manage financial resources effectively for a lifetime of financial well-being. Until them, financial literacy had the clearest and widely accepted definition. At the same time, PACFL also clearly defines the scope of "financial literacy" and "financial knowledge". Since then, researches on financial literacy at home and abroad have entered a new stage.

\section{QUESTIONNAIRE DESIGN AND QUANTITATIVE METHODS}

\section{A. Questionnaire Design Ideas}

The questionnaire is based on the financial needs and financial literacy of rural residents in Wuling mountainous area, covering the basic conditions, financial awareness, financial knowledge, financial behavior, financial skills, financial education and Internet use. The questionnaire is strict in logic, coherent, rigorous in structure, easy to understand, and close to the research theme. 


\section{B. Quantitative Evaluation Method for Rural Residents' Financial Literacy}

Four dimensions are used, namely financial awareness, financial knowledge, financial behavior and financial skills, as the primary indicators, and set secondary indicators under each primary indicators, to evaluate the financial literacy of the sample farmers. In order to understand the financial literacy of rural residents in Wuling mountainous area more intuitively, different scores are assigned according to the respondents' responses for quantitative processing. Since the financial knowledge mastered by rural residents is one-sided, in order to avoid too large gap between the final scores caused by this factor, the score for each question is controlled between $0-3$. The category and score of each question are different, which have different functions, so the coefficient of variation is used and the financial awareness, financial knowledge, financial behavior, and financial skill scores are weighted by 3:3:2:2. The specific evaluation criteria are as follows: (See "Table I")

TABLE I. EVALUATION SYSTEM FOR THE FINANCIAL LITERACY OF RURAL RESIDENTS

\begin{tabular}{|c|c|c|}
\hline $\begin{array}{l}\text { Primary } \\
\text { Indicator }\end{array}$ & $\begin{array}{l}\text { Secondary } \\
\text { Indicator }\end{array}$ & Investigation Content \\
\hline \multirow{4}{*}{$\begin{array}{l}\text { Financial } \\
\text { awareness }\end{array}$} & $\begin{array}{l}\text { Risk } \\
\text { awareness }\end{array}$ & $\begin{array}{l}\text { Risk appetite, awareness of risk } \\
\text { aversion }\end{array}$ \\
\hline & $\begin{array}{l}\text { Credit } \\
\text { awareness }\end{array}$ & $\begin{array}{l}\text { Understanding of credit and } \\
\text { awareness of credit behavior }\end{array}$ \\
\hline & $\begin{array}{l}\text { Financial } \\
\text { management } \\
\text { awareness }\end{array}$ & $\begin{array}{l}\text { Formulate revenue and } \\
\text { expenditure plans or not, financial } \\
\text { management willingness }\end{array}$ \\
\hline & $\begin{array}{l}\text { Insurance } \\
\text { awareness }\end{array}$ & Understanding of insurance \\
\hline \multirow{4}{*}{$\begin{array}{l}\text { Financial } \\
\text { knowledge }\end{array}$} & $\begin{array}{l}\text { Bank } \\
\text { knowledge }\end{array}$ & $\begin{array}{l}\text { Banking knowledge, } \\
\text { understanding of illegal interest } \\
\text { rate, number of credit cards }\end{array}$ \\
\hline & $\begin{array}{l}\text { Insurance } \\
\text { knowledge }\end{array}$ & Insurance concept \\
\hline & $\begin{array}{l}\text { Financial } \\
\text { management } \\
\text { knowledge } \\
\end{array}$ & Financial literacy \\
\hline & $\begin{array}{l}\text { Financial } \\
\text { knowledge }\end{array}$ & $\begin{array}{l}\text { Understanding of local financial } \\
\text { structure, financial knowledge, } \\
\text { risk perception }\end{array}$ \\
\hline \multirow{4}{*}{$\begin{array}{l}\text { Financial } \\
\text { behavior }\end{array}$} & $\begin{array}{l}\text { Financing } \\
\text { behavior }\end{array}$ & $\begin{array}{l}\text { Debit and credit status, credit } \\
\text { card use }\end{array}$ \\
\hline & $\begin{array}{l}\text { Insurance } \\
\text { behavior }\end{array}$ & Purchase of different insurances \\
\hline & $\begin{array}{l}\text { Financial } \\
\text { management } \\
\text { behavior }\end{array}$ & $\begin{array}{l}\text { Financing channels and interest } \\
\text { rate comparison }\end{array}$ \\
\hline & $\begin{array}{l}\text { Other } \\
\text { behaviors }\end{array}$ & $\begin{array}{l}\text { Usage of online banking, mobile } \\
\text { banking and third-party payment }\end{array}$ \\
\hline \multirow{2}{*}{$\begin{array}{l}\text { Financial } \\
\text { skills }\end{array}$} & $\begin{array}{l}\text { Resource } \\
\text { utilization } \\
\text { capacity }\end{array}$ & $\begin{array}{l}\text { Business processing channels, } \\
\text { daily consumption methods }\end{array}$ \\
\hline & $\begin{array}{l}\text { Interest rate } \\
\text { calculation } \\
\text { ability }\end{array}$ & Interest rate calculation ability \\
\hline
\end{tabular}

\section{INVESTIGATION ON THE FINANCIAL LITERACY OF RURAL RESIDENTS IN WULING MOUNTAINOUS AREA}

\section{A. Financial Awareness}

In this investigation, 1595 valid questionnaires are collected. According to the above-mentioned quantification method for financial literacy, the average score for financial awareness of rural residents in Wuling mountainous area is 0.624 , the highest score is 1 , the lowest score is 0.25 , and the coefficient of variation is 0.1754 , which is in a good grade, indicating that the overall financial awareness of the rural residents in the area is relatively high. $16.36 \%$ of the sample farmers' financial awareness is at an excellent level, and $74.23 \%$ at a good level; the sum of the two data show that $90.69 \%$ of the sample farmers' financial awareness is at an excellent / good stage, and only $9.40 \%$ of the sample farmers are at a medium level, indicating the rural residents in Wuling mountainous area basically have a correct financial awareness.

Among the four secondary indicators that constitute financial awareness, credit awareness and risk awareness get higher scores, while financial management awareness and insurance awareness are relatively poor, but they are all above a medium level (inclusive). The average score of credit awareness and risk awareness is 0.89 and 0.73 respectively; $85.45 \%$ of the sample farmers agree that credit is very important, indicating that the sample farmers have high credit cognition, and the ratio of debt repayment on time also reaches $74.80 \%$; most sample farmers adhere to basic credits and repay debts on time; however, only $8.28 \%$ of sample farmers are willing to bear high risks, while most sample farmers are unwilling to bear high returns under high risks, and have a strong sense of risk aversion. In contrast, the sample farmers have relatively poor knowledge of financial management and insurance, the average score of financial management awareness is 0.52 , and the average score of insurance awareness is 0.36 , which are the lowest. According to the data, only 111 people among these samples have purchased financial management products, accounting for $6.96 \%$. In addition, 427 sample farmers set up revenue and expenditure plans, accounting for $26.77 \%$; in terms of insurance awareness, only $27.59 \%$ of the sample farmers know that insurance can reduce risk. From the above analysis, it can be seen that farmers in Wuling mountainous area do not have a deep understanding of financial management and insurance, and their participation is relatively low.

\section{B. Financial Knowledge}

The average score of financial knowledge of rural residents in Wuling mountainous area is 0.44 , the highest score is 0.81 , the lowest score is 0.15 , and the coefficient of variation is 0.2294 , which is at a medium level, indicating that the overall financial knowledge of rural residents in the area is at a medium level. Only $0.13 \%$ of the sample farmers' financial knowledge is at an excellent level, $34 \%$ at a good level, $63.86 \%$ at a medium level, and $2.01 \%$ at a poor level, which indicates that the sample farmers' financial knowledge is concentrated at a medium and good level. Only $34.13 \%$ of 
the sample farmers have reached excellent / good levels, indicating that the financial knowledge of the rural residents in Wuling mountainous areas is not in a good condition and there is room for improvement. Among the four secondary indicators that constitute financial knowledge, the scores for financial common sense and insurance knowledge are better, both above 0.5, while bank knowledge and financial management knowledge are relatively poor, with an average score of 0.37 and 0.23 , respectively. This indicates that the sample farmers can basically grasp the financial common sense and insurance common sense required in daily agricultural production and life. In contrast, since financial institutions such as banks and securities are relatively scattered in remote areas, often far away, the financial management activities of rural residents are single and few, with few contact opportunities, and the sample farmers' understanding and mastery of bank knowledge is not in place.

For the bank knowledge investigated, 13 basic skills are selected including "how to distinguish counterfeit currency", "how to calculate deposit and loan interests", "how to use ATM and POS machine". Among the sample farmers investigated, most of the farmers can master 1 3 financial common senses, accounting for $62.67 \%$; $19.69 \%$ of the sample farmers can master 4 7 financial common senses, $1.25 \%$ of the sample farmers can master more than 7 financial common senses, and only $1.67 \%$ of sample farmers cannot master any financial common sense.

Among the 13 financial common senses investigated, "how to distinguish counterfeit currency" is mastered by the most sample farmers. Among the 1595 sample farmers investigated, 1458 indicate that they can basically grasp the method of distinguishing genuine and counterfeit currency, indicating that sample farmers can safeguard their rights in daily life and transactions, reflecting their caution and high risk prevention awareness; the next is "how to use ATM and POS machine", accounting for $41.11 \%$, which indicates that there have been effective promotion of bank outlets and infiltration of mobile payment in the places where some of the sample farmers live, but there are few users, and most of the investigated areas still do not have such facilities; the next is "computing deposit and loan interests" and "using online banking", accounting for $31.48 \%$ and $27.15 \%$ respectively, which indicates that most sample farmers can still not master the loan conditions and the use of financial mobile terminals, and that the sample farmers do not know how to apply for loans and have difficulty in loans, and their acceptance of new financial service tools is weak; fewer people master "credit card use", "bank loan process", "bank card payment", "futures, insurance", accounting for $13.92 \%$, $13.86 \%, 8.78 \%$ and $7.34 \%$, respectively, which indicates that the sample farmers are not very familiar with banking business and derivatives, and are basically not able to master, with big problem; the remaining 5 senses, including "foreign exchange", "fund" and "trust", account for 5.7\%, indicating that the sample farmers almost have no knowledge of such financial products. In addition, when investigating whether the sample farmers can distinguish the illegal interest rate, $18.81 \%$ of the sample farmers say that they cannot distinguish, $62.01 \%$ of the sample farmers make mistakes, and $19.18 \%$ of the sample farmers can correctly distinguish the illegal interest rate. This indicates that the sample farmers have certain legal awareness in private financing, but they are still weak in correctly mastering the financial laws and common senses.

\section{Financial Behavior}

The highest score of the overall financial behavior of Wuling mountainous area is 0.833 , the lowest score is 0.167 , the average score is 0.463 , and the coefficient of variation is 0.257 . It can be seen that the financial behavior of most of the rural residents in the area is at a medium level, and there are great differences among financial behaviors.

The financial behavior of most of the rural residents in the area is at a medium level, accounting for $71.35 \%$; only $0.44 \%$ of the residents' financial behavior score is at an excellent level, indicating that few people among the sample farmers have excellent financial behaviors; there are a few residents with good financial behavior scores, accounting for $21.94 \%$; there are still residents with poor financial behavior scores, accounting for $6.27 \%$, and this part of residents are incapable of using the local inclusive financial policy, while the influence poverty alleviation cannot be underestimated. Next, the financial behavior of residents in the area will be specifically measured from four modules: financing behavior, insurance behavior, financial management behavior and other behaviors.

Among the secondary indicators for the rural residents in Wuling mountainous area, only the indicator financial behavior achieve a good level, while insurance behavior, financial management behavior and other behaviors are all at a medium level. Although financing behavior is at a good level, its score is only 0.56 , which indicates that although the residents in the area have certain financing knowledge reserve and financing ability, the advantage of financing behavior is not significant, and there is large room for improvement. The scores of insurance behavior, financial behavior and other behaviors are concentrated between 0.25 and 0.35 . Among them, the score for insurance behavior is the lowest, only 0.26 , which indicates that the insurance utilization of residents in the area is low, and the rural residents' insurance utilization capacity needs to be improved, thus effectively reducing risks and improving security.

Among the 1595 valid questionnaires, 1031 residents have successfully obtained loans through private financing, accounting for $64.64 \%$; 388 residents have applied for loans to formal financial channels, accounting for $24.33 \%$; the data indicate that the success rate of private financing is high; compared with loans to financial channels, rural residents prefer private financing, especially to relatives and friends. According to the statistics of the samples' overall loan channels, among the 388 residents who have loaned to formal financial channels, they have only tried 1-4 kinds of loan channels; among them, most people (242 people) loan to rural credit cooperatives, accounting for $62.37 \%$; 55 people have loaned to the Agricultural Bank, accounting for $14.18 \% ; 15,28$ and 53 people have loaned to the financial institutions such as the Postal Savings Bank, Rural Bank and 
other banks, no one has loaned to fund cooperation society or small loan companies; the above data show that in rural areas, rural credit cooperatives and agricultural banks play a leading role in rural residents' loans, but other commercial banks and microfinance institutions have lower effect on supporting agriculture in the area. At present, only 349 people have borrowing demand, accounting for $21.88 \%$; this indicates that the rural residents' loan demand in this area is relatively low, which may be related to their awareness of risk aversion.

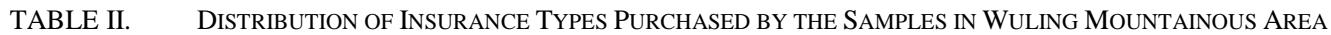

\begin{tabular}{|c|c|c|c|c|c|c|}
\hline & $\begin{array}{l}\text { Rural Cooperative } \\
\text { Medical Insurance }\end{array}$ & Rural Pension Insurance & $\begin{array}{l}\text { Property } \\
\text { Insurance }\end{array}$ & $\begin{array}{l}\text { Motor Vehicle } \\
\text { Insurance }\end{array}$ & $\begin{array}{l}\text { Agricultural } \\
\text { Insurance }\end{array}$ & Other \\
\hline Number of people & 1116 & 890 & 9 & 325 & 33 & 88 \\
\hline Proportion & $69.97 \%$ & $55.80 \%$ & $0.56 \%$ & $20.38 \%$ & $2.07 \%$ & $5.52 \%$ \\
\hline
\end{tabular}

"Table II" shows the distribution of insurance types purchased by the samples in Wuling mountainous area. It can be found that more than half of the people have purchased rural cooperative medical insurance and rural pension insurance, indicating that China's inclusive financial policy has achieved remarkable success in popularizing cooperative medical insurance and pension insurance; motor vehicle insurance also reaches $20.38 \%$, indicating that the owning rate of motor vehicles among rural residents has increased compared with previous years; for agriculture on which farmers depend for survival, the insurance rate is only $2.07 \%$, which indicates that the farmers in the area have not enough knowledge of agricultural insurance, so leading to a greater risk of unpredictable loss of agricultural production; among the five types of insurance shown in the above table, the purchasing rate of property insurance is only $0.56 \%$, indicating the residents in the area have weak property insurance awareness, and targeted publicity can be carried out.

The number of people using online banking, mobile banking, and third-party collection and payment to handle the payment and transfer business is generally low. People enjoying online banking and mobile banking services account for about $25 \%$, less than a quarter of the total number of people, which indicates that the popularity of these two convenient financial services needs to be strengthened in the area. In daily life, $49.59 \%$ of people use third-party payment and collection, which close to half; this indicates that third-party payment software such as Alipay and WeChat is popular in the area, which can bring convenience to residents' lives, but there is still room for improvement of popularity.

\section{Financial Skills}

The average score of financial skills in Wuling mountainous area is 0.4929 , the highest score is 1 , the lowest score is 0.125 , and the coefficient of variation is 0.3403 , indicating that the overall financial skills of the sample farmers are at a medium level, and the financial skills are quite different among the sample farmers.

It can be seen that $45.58 \%$ of the sample farmers' financial skills are at a good level; the next is medium level, accounting for $40.56 \%$; samples below 0.25 only account for $0.63 \%$, and the samples with excellent level account for $13.23 \%$; this indicates the rural residents in that Wuling mountainous area master the basic financial skills relatively well, but there are also two problems: on the one hand,
$41.19 \%$ of the residents still have not reached a good level, the samples with excellent level only account for $13.23 \%$, and the number of people with good financial skills is too small. Next the financial skills of the rural residents in the area will be analyzed from the aspects of financial resource utilization capacity and interest rate calculation.

The score for the financial resource utilization ability of rural residents in Wuling mountainous area is 0.45 , and the interest rate calculation ability is 0.42 , both at a medium level, but the score is close to 0.50 , indicating that the overall utilization level of rural residents' resource utilization level and interest rate calculation ability is equivalent, but the mastery degree of financial skills is not enough. $70.97 \%$ of the rural residents in the area handle banking business through bank counters or agents, $21.69 \%$ through ATM, but only $3.95 \%$ of people use online banking, indicating that the rural residents in the area mainly handle the basic financial business through the staff of relevant financial institutions. Since ATM and online banking have relatively high requirements for users, only $25.64 \%$ of the rural residents in Wuling mountainous area use them.

$38.37 \%$ of the sample farmers can accurately calculate the interest rate based on the annual interest rate, but $42.70 \%$ of the sample farmers make mistakes in calculation, and $18.75 \%$ cannot calculate. According to the above data, $61.45 \%$ of the sample farmers cannot calculate interest, accounting for more than $60 \%$, which indicates that the interest rate calculation ability of most of the rural residents in the area does not reach the standard.

\section{CONCLUSIONS AND PROPOSALS}

\section{A. Research Conclusions}

The quantitative analysis is conducted after assignment based on the questionnaires of respondents with the four dimensions: financial awareness, financial knowledge, financial behavior and financial skills. The assessment scores of the sample farmers' financial literacy are mainly distributed in the range $0.40-0.60$; the lowest score is 0.33 , and the highest score is 0.77 . In the assessment for basic knowledge, the scores of the rural residents in the area are mainly distributed in the range $0.40-0.60$, failing to reach the excellent / good level. In addition, the distributional difference in sample scores is small, indicating that the financial literacy of most rural residents in the area is at a medium level, and the difference in the financial literacy level among rural residents is small. (See "Fig. 1") 
becoming richer with the preservation and appreciation of assets.

3) Strengthening the construction of hardware and software facilities: The construction of financial infrastructure is the premise for providing financial services. To vigorously develop rural finance, it is necessary to strengthen the construction of relevant infrastructure. First of all, banking services should be rooted in the countryside, and ATM should be added in rural pivots to facilitate rural residents to handle savings business. Each administrative village can arrange and contact staff to effectively bring banking services to the village and serve the village. Secondly, it is necessary to improve the construction of communication and network facilities, provide rural residents with smooth information exchange channels to understand financial information and handle financial business through the network, and make up for the backward situation of information dissemination; finally, it is necessary to improve the road construction and passenger transportation system in rural areas, enable rural residents to travel conveniently and safely, and promote the external exchange and study of residents in rural areas.

\section{REFERENCES}

[1] Noctor M, Stoney S, Stradling R. Financial literacy: a discussion of concepts and competences of financial literacy and opportunities for its introduction into young people's learning $[\mathrm{J}]$. National Foundation for Educational Research, 1992.

[2] Braunstein, Sandra, and Carolyn Welch. Financial literacy: An overview of practice, research, and policy [J]. Fed. Res. Bull.,2002, $88: 445$.

[3] Fox, Jonathan, Suzanne Bartholomae, and Jinkook Lee. Building the case for financial education[J].Journal of consumer affairs,2005,39(1) 195-214.

[4] Chen, Haiyang, and Ronald P. Volpe. Gender differences in personal financial literacy among college students [J]. Financial services review, 2002, 11(3): 289-308.

[5] Rhine, Sherrie, and Maude Toussaint - Comeau. Adult Preferences in the Delivery of Personal Financial Information[J]. Financial Counseling and Planning, 2002,13 (2): 11 - 25.

[6] Koenig, Lori. Financial Literacy Curriculum: The Effect on Offender Money Management Skills [J]. Journal of Correctional Education, 2007, 58 (1): $43-56$

[7] Vitt, Lois A., et al. Personal finance and the rush to competence Financial literacy education in the US[pdf]. Institute for SocioFinancial Studies Working Paper, http://www. isfs. org/documentspdfs/rep-finliteracy. 2000.

[8] Zhang Huanhuan, Xiong Xueping, Research on the Characteristics and Influencing Factors of Financial Literacy of Rural Residents from the Perspective of Inclusive Finance [J], Research of Agricultural Modernization, 2017.38(6): 1026-1035. (in Chinese)

[9] Yin Zhichao, Song Quanyun, Wu Yu, Financial Knowledge, Investment Experience and Family Asset Selection [J], Economic Research Journal, 2014(4). (in Chinese) provide diversified products with different conditions of time limit, amount, interest rate and risk, and actively help farmers to get rich; so that farmers can enjoy the same financial services provided by financial institutions as urban residents. It is necessary to improve the credit evaluation system for rural residents, vigorously develop financial markets, and help rural residents who are gradually 